\title{
Alterations in Nutritional Status and Body Composition in COPD Patients
}

Joaquim Gea, MD, PhD, Cristina Estirado, MD and Esther Barreiro, MD, PhD

Respiratory Medicine Department, Hospital del Mar IMIM, DCEXS, Universitat Pompeu Fabra, CIBERES, ISCIII, Barcelona, Spain

\section{ABSTRACT}

This review focuses on nutritional abnormalities, one of the most prominent extrapulmonary manifestations occurring in chronic obstructive pulmonary disease (COPD). Diagnosis is usually made by either anthropometry or determination of body composition. Deficiencies in nutritional status, such as body weight and muscle mass loss, are the result of an interaction of several factors, including the imbalance between energy supply and requirements, tobacco, low physical activity, and systemic inflammation. These factors essentially determine the predominance of protein breakdown over synthesis. The loss of body weight and lean mass leads to muscle dysfunction and exercise limitation, also having a negative impact on exacerbations and mortality. Therapies include changes in lifestyle and nutritional supplements. Anabolic drugs may be administered in some cases. Obesity is also very prevalent in COPD patients, being associated with cardiovascular and metabolic comorbidities. Although, paradoxically, moderate obesity appears to reduce mortality, healthy lifestyle habits are recommended to avoid morbid obesity. (BRN Rev. 2017;:56-71) Corresponding author: Joaquim Gea, JGea@parcdesalutmar.cat

Keywords: Diet. Exercise. Low body weight. Muscle dysfunction. Nutrition. Obesity. Protein. 


\section{INTRODUCTION}

Chronic obstructive pulmonary disease (COPD) is a highly prevalent disorder, characterized by its complexity and heterogeneous presentation $^{1}$. COPD not only involves airways and lung parenchyma, but is also associated with systemic manifestations and different comorbidities. Moreover, additional deleterious circumstances, such as aging and an unhealthy lifestyle, are often present. Nutritional abnormalities stand out among the systemic manifestations of COPD for their frequency and impact on patients' lives. In this sense, it is very well known that deficits in nutritional status impair prognosis, bringing a poorer quality of life, higher exacerbation rate, and increased mortality ${ }^{2,3}$. Moreover, one of the most important consequences of lean mass loss is muscle dysfunction, which in turn results in reduced exercise capacity and physical activity ${ }^{3-5}$. To date much less attention has been paid to the association of COPD with obesity. The latter is also highly prevalent, being associated with cardiovascular and metabolic comorbidities ${ }^{6}$. This review will focus primarily on nutritional deficiencies and their consequences, and only a short section will be devoted to obesity and its implications for patients.

\section{EPIDEMIOLOGY}

The actual prevalence of deficits in nutritional status is relatively high, but depends both on the criteria used for diagnosis and the population that has been studied. In general, diagnosis is based on body mass index (BMI, ratio between weight in $\mathrm{kg}$ and height in square meters), derived from anthropometric measurements, and/or fat-free mass or lean index (FFMI, a variable that derives from a compartmental model of body composition, where fat free mass is specifically considered), being generally obtained with bioelectrical impedance or dual-energy X-ray absorptiometry (DEXA). According to BMI, the prevalence of nutritional and body composition deficiencies in COPD patients from Northern, Eastern, and Central Europe as well as North America ranges between 15-50\% ${ }^{7,8}$. By contrast, the prevalence in Mediterranean countries appears to be lower, with figures ranging between $3-20 \% 9,10$. These discrepancies have been partially attributed to different lifestyles linked to cultural specificities (diet, physical activity), discrepancies in the variable and threshold values used for diagnosis by different authors (see next section), and healthcare level where patients have been recruited. In fact, the highest prevalences have generally been reported in individuals recruited in rehabilitation centres or hospital clinics, while they are much lower in other environments with less selection bias. An important issue is the potential difficulties of nutritional deficiency diagnosis in female patients, since here a significant discrepancy may occur between BMI and FFMI. The latter detects the loss of lean body mass, even though body weight remains stable or even increases ${ }^{8}$. Nutritional abnormalities affect not only muscle mass, but can also have an impact on bone and fat tissues, reaching a state of cachexia in the more advanced situations. Finally, it should be noted that nutritional deficiencies have been associated with different COPD profiles or phenotypes, especially the emphysematous type (pink puffer), and those patients with muscle manifestations ${ }^{11}$. 
In any case, regardless of its actual prevalence, the clinical negative impact of underweight and loss of muscle mass is very important for COPD patients (Fig. 1), requiring both an early diagnosis and appropriate management. In fact, it has been clearly demonstrated that even moderate increases in body weight can improve quality of life and prognosis in patients with nutritional abnormalities ${ }^{2}$.

\section{DIAGNOSIS}

As already mentioned, nutritional abnormalities can be easily detected using different variables and measuring instruments (Fig. 2). The easiest to be obtained but less specific are anthropometric variables such as body weight, percentage of ideal body weight (\%IBW) or BMI. Regarding IBW, values under 80-85\% indicate that there is a deficit in nutritional status $^{12}$, while the BMI threshold is usually set at $18.0-18.5 \mathrm{~kg} / \mathrm{m}^{2} 13$, although some authors prefer higher values $\left(20-21 \mathrm{~kg} / \mathrm{m}^{2}\right)$. The nutritional problem can be considered as already serious if the $B M I$ is below $16 \mathrm{~kg} / \mathrm{m}^{2}$, and if it is less than $15 \mathrm{~kg} / \mathrm{m}^{2}$ it is considered as very severe ${ }^{13}$. A more specific approach is to determine the FFMI, using bioelectrical impedance or DEXA ${ }^{3,14}$. Both techniques provide an accurate approximation of muscle mass, which in the case of DEXA can also be compartmentalized in body portions (i.e. trunk, upper or lower extremities). The most accepted FFMI limit to define a loss of lean mass is $16 \mathrm{~kg} / \mathrm{m}^{2}$ in men, and $15 \mathrm{~kg} / \mathrm{m}^{2}$ in women ${ }^{8}$. However, higher values for men $\left(18 \mathrm{~kg} / \mathrm{m}^{2}\right)$ and lower values for women $\left(14.5 \mathrm{~kg} / \mathrm{m}^{2}\right)$ have been proposed for Mediterranean populations ${ }^{15}$. There are other methods that can also be used to assess nutritional status, although
AIRWAYS and LUNG PARENCHYMA

- Destruction of septa, elongation of airspaces

- Tendency to alveolar collapse

IMMUNE SYSTEM

- Immunity abnormalities facilitate infections

SKELETAL MUSCLE

- Respiratory muscle dysfunction: ventilatory problems

- Limb muscle dysfunction: exercise limitation, low physical activity

CARDIOCIRCULATORY SYSTEM

- Cardiac muscle dysfunction, heart failure

BONES

- Osteoporosis, risk of fractures

- OTHERS

- Anaemia, coagulation abnormalities, iron deficiency, etc.

Figure 1. Consequences of nutritional abnormalities on different tissues and systems.

they are much less employed. This is the case for image techniques, such as computed tomography, magnetic resonance, and ultrasounds, which can quantify the mass of specific muscle groups or localized fat mass ${ }^{16-18}$, providing even functional information ${ }^{17,19}$. Triceps skinfold or thigh circumference are some of the additional anthropometric measurements that can be used, but they have fallen into disuse in recent decades. Finally, there are more sophisticated techniques such as air displacement plethysmography, densitometry by immersion in water, deuterium dilution, and isotopic methods $3,11,14$, although their use is either cumbersome or expensive. Blood analysis can also be useful to assess nutritional status. More specifically, determinations of serum total proteins, albumin fraction, cholesterol, and prothrombin time have been used by different authors ${ }^{3}$. 


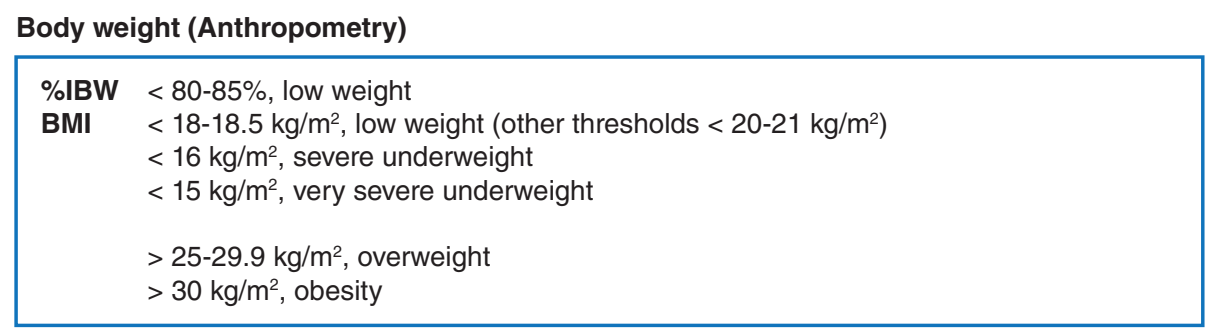

Body composition (Impedanciometry or DEXA)

$\begin{array}{ll}\text { FFMI } & <16 \mathrm{~kg} / \mathrm{m}^{2} \text { (men) and }<16 \mathrm{~kg} / \mathrm{m}^{2} \text { (women), low FFMI } \\ & <18 \mathrm{~kg} / \mathrm{m}^{2} \text { (men) and }<14.5 \mathrm{~kg} / \mathrm{m}^{2} \text { (women), low FFMI in Mediterranean populations } \\ & \\ \text { FMI } & >6.6 \mathrm{~kg} / \mathrm{m}^{2} \text { (men) and }>9.5 \mathrm{~kg} / \mathrm{m}^{2} \text { (women), obesity } \\ \text { PBF } & >25 \% \text { (men) and }>35 \% \text { (women), obesity }\end{array}$

Additional methods used in diagnosis: Other anthropometric measurements (triceps skinfold, thigh or biceps circumference), blood analysis (total proteins, albumin, cholesterol, prothrombin), image techniques (CT, MRI, echography, PET), air displacement plethysmography,

spectrophotometry, densitometry by immersion in water, deuterium dilution, isotopic methods.

Figure 2. Techniques and thresholds used in the diagnosis of nutritional abnormalities.

\%IBW: percentage of ideal body weight; BMI: body mass index; CT: computed tomography; DEXA: dual-energy x-ray absorptiometry; FFMI: fat free mass index; FMI: fat mass index; MRI: magnetic ressonance imaging; PBF: percentage of body fat;

PET: positron emission tomogrpahy.

Surprisingly, although an extremely underweight patient was already included in the two classical COPD phenotypes, recent guidelines such as GOLD or GesEPOC have not highlighted the frequent presence of nutritional abnormalities ${ }^{1,20}$. This is probably due, at least in part, to the lack of a well defined therapy for these problems. In fact, the multidimensional BODE score and its derivates are practically the only ones that have included BMI in those variables used to establish the severity and prognosis of COPD ${ }^{21}$.

\section{ETIOLOGICAL FACTORS}

It is commonly accepted that body weight and muscle mass loss occurring in COPD is due to the interaction of different factors. These include lifestyle circumstances as well as metabolic and hormonal imbalances, among others, all of them leading to a predominance of catabolism on anabolism (Fig. 3). Their interaction and the predominance of one or another factor is specific to each particular patient.

\section{Factors related to lifestyle habits}

\section{LOW LEVEL OF PHYSICAL ACTIVITY AND SEDENTARY LIFESTYLE}

This factor is very common in COPD patients and results in cardiovascular and skeletal 


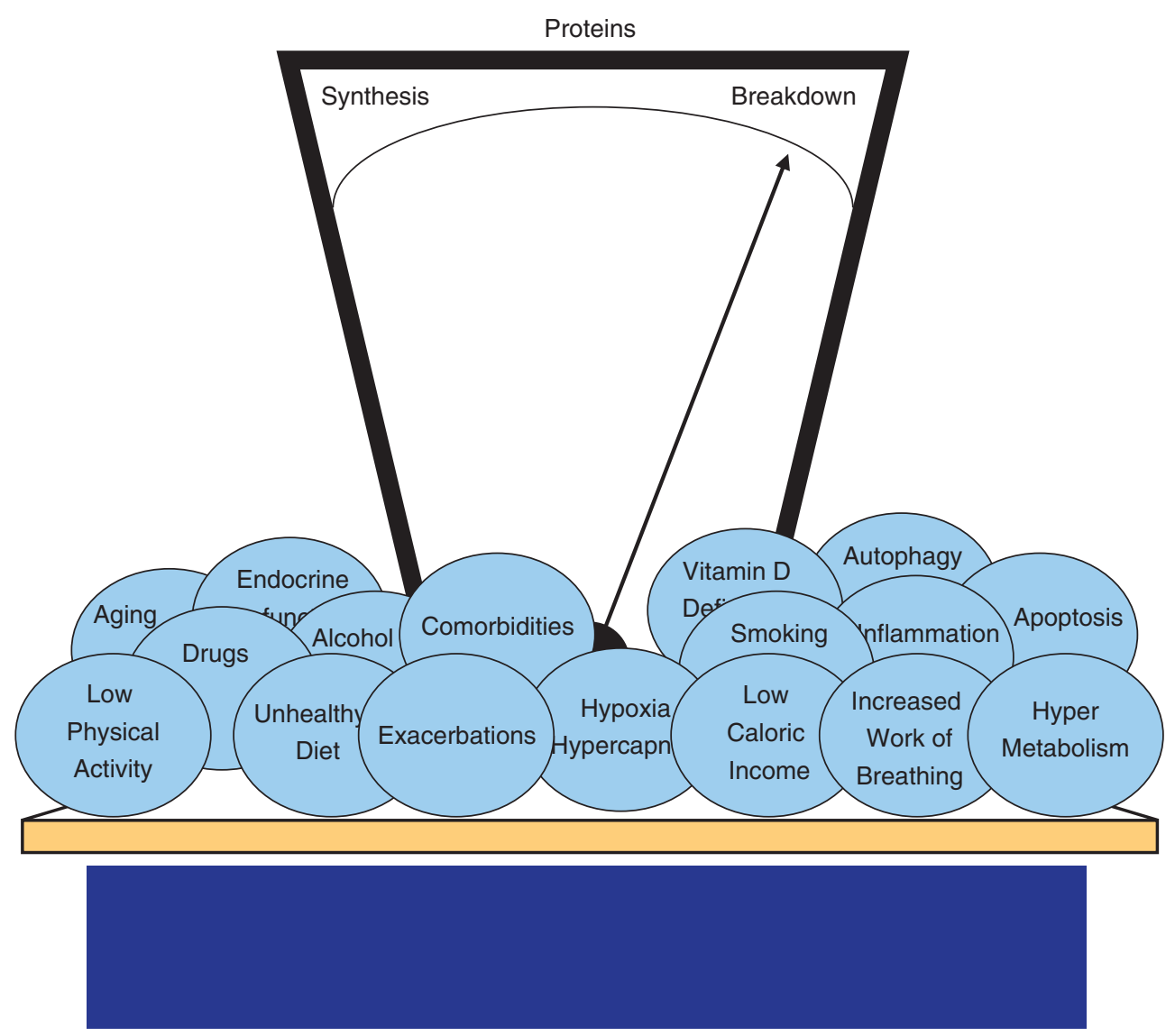

FIgURE 3. Factors and biological mechanisms involved in nutritional status deficiencies in COPD.

muscle deconditioning, also having a negative impact on the immune status, exacerbations, and mortality ${ }^{22}$. Moreover, reduction in physical activity can induce biological events such as increases in the level of systemic inflammation and decreases in muscle protein synthesis ${ }^{23}$. However, it should be noted that an excessive increase in the level of activity, as in intense exercise, may also induce systemic oxidative stress and adverse effects on muscles in untrained subjects ${ }^{24}$. Therefore, increases in physical activity must be progressive and well controlled in COPD patients.

\section{SMOKING STATUS}

Tobacco smoking has an anorectic effect and can reduce body weight and muscle mass through induction of systemic inflammation and oxidative stress, release of leptin, and an imbalance between protein synthesis and breakdown ${ }^{25,26}$.

\section{ALCOHOL ABUSE}

Alcohol abuse is associated with smoking in many cases ${ }^{27}$. In fact, smokers are four times 
more likely to have alcohol dependence than non-smokers ${ }^{27}$. As a result, $7-20 \%$ of COPD patients are heavy drinkers ${ }^{28}$, a factor that has been associated with higher mortality and poorer quality of life ${ }^{28}$. Moreover, alcohol abuse is involved in weight, fat mass, and muscle mass loss in the general population ${ }^{29}$. Although no studies to date have evaluated the role of alcohol abuse in underweight COPD patients, its involvement is very likely.

\section{UnHEALTHY DIET}

As mentioned, the caloric intake of COPD patients is often inadequate, not matching their energy requirements. Moreover, they consume less carbohydrates, proteins, vitamins A, B6, B9, B12, C, D, and E, and less carotenes and omega 3 fatty acids than healthy subjects of the same age ${ }^{30,31}$. These deficits are more pronounced in patients with weight loss ${ }^{30,31}$.

\section{Other deleterious factors}

\section{EXACERBATIONS}

These acute episodes increase the level of local and systemic inflammation markers as well as those of leptin. Moreover, anorexia, fever, reduced physical activity, and increases in work of breathing are often added to this adverse metabolic picture ${ }^{11}$.

\section{IMBALANCE BETWEEN ENERGY EXPENDITURE AND CALORIC INTAKE}

A hypermetabolic status occurs in COPD in addition to the abovementioned increase in the work of breathing ${ }^{32}$. Both circumstances increase energy needs ${ }^{32}$, which can not be supplied with normal caloric intake. This scenario worsens if the latter becomes reduced due to the presence of cofactors such as smoking, dyspnea, inflammation, or even an exacerbation.

\section{HYPOXIA AND HYPERCAPNIA}

Hypoxia induces inflammation and oxidative stress in different body tissues, deteriorating both metabolism and the actions of some peptides and hormones involved either in appetite or the maintenance of muscle, bone, and fat masses. This is the case for leptin, ghrelin, and AMP-activated protein kinase, which can induce autophagy and muscle apoptosis while reducing mitochondrial synthesis (biogenesis) ${ }^{33}$. In contrast, the main impact of hypercapnia in nutritional status is indirect, through the induction of respiratory acidosis. This in turn will result in less energy stores and an imbalance between protein synthesis and breakdown ${ }^{34}$.

\section{ENDOCRINE DYSFUNCTION}

The effect of anabolic hormones is frequently altered in COPD patients. This is the case of androgens, since a variable prevalence of hypogonadism has been described in COPD men with reduced muscle mass ${ }^{35}$. Furthermore, a decrease in growth hormone levels (GH) secreted by the adenohypophysis, and/ or a dysfunction in the powerful anabolic axis that includes its hypothalamic-releasing factor, $\mathrm{GH}$, and insulin-like growth factor 1 (IGF-1) have also been reported ${ }^{36,37}$. The IGF-1 
participates in growth and muscle repair, while helping in the maintenance of bone mass and immunological status ${ }^{37}$.

\section{VITAMIN D DEFICIENCY}

A significant number of COPD patients show a decreased intake of vitamin $\mathrm{D}$ and calci$\mathrm{um}^{31}$. This circumstance can also be associated with a reduction in outdoor physical activities, with a lack of sunlight exposure, which is required for vitamin D endogenous synthesis. Therefore, it is not surprising that vitamin $\mathrm{D}$ deficiency ranges between $40 \%$ in patients with mild COPD and rises to $77 \%$ in those with more severe disease ${ }^{38}$. It is well known that vitamin D plays an essential role in the mineralization and maintenance of bone mass, but it also has important effects on muscle mass, the cardiovascular system, and immune status ${ }^{38}$. In fact, between 20-60\% of COPD patients have osteoporosis ${ }^{39}$, a factor that can contribute to both underweight and an increased risk of fractures (Fig. 1).

\section{AgING}

Aging by itself can also induce loss of body weight and even sarcopenia (loss of muscle mass associated with senescence) and osteoporosis. These effects on anthropometry and/ or body composition can be further impaired in the presence of $\mathrm{COPD}^{40}$.

\section{COMORBIDITIES}

Other chronic diseases are commonly associated to COPD due to both sharing the same aetiological factors and the effects of aging in many patients. Chronic heart failure, diabetes, and cancer are among the most frequent comorbid conditions associated with nutritional status deficiencies ${ }^{3}$.

\section{DRUGS}

Although other drugs can impair muscle structure and/or function, systemic glucocorticoids, which can cause chronic or acute myopathy and muscle loss due to a reduced synthesis of structural proteins ${ }^{41}$, should be specially highlighted.

\section{Biological mechanisms}

\section{LOSS OF PROTEOSTASIS}

Probably the most important mechanism involved in the reduction of body weight and lean mass is the imbalance between reduced protein synthesis and an increased protein breakdown ${ }^{3,11,37}$. This imbalance has devastating effects on different tissues and physiological functions (Fig. 4). It occurs due to factors mentioned in the preceding section and additional biological mechanisms, such as inflammation and oxidative stress, taking place at both systemic and local levels (see below) $)^{3,42,43}$. On the one hand, a reduction in protein synthesis signalling has been observed in limb muscles of COPD patients ${ }^{44,45}$. This is probably due both to the low availability of amino acids to assemble new proteins and a failure in the synthesis pathways ${ }^{45}$. The former, in turn, appears to be secondary to a reduced protein intake ${ }^{30}$ and the low uptake by skeletal muscles ${ }^{46}$, among other factors. 


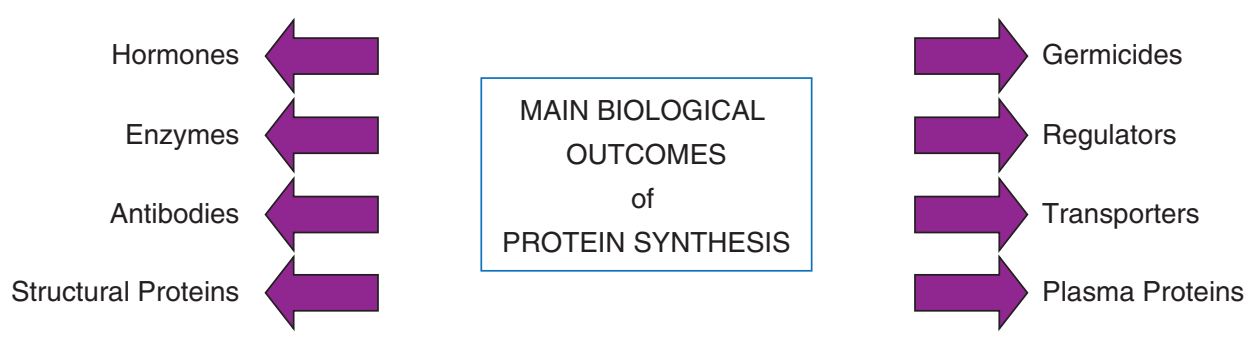

Figure 4. Main biological outcomes that become impaired by a reduction in protein content secondary to the loss of proteostasis.

Regarding protein synthesis itself, it has been described that anabolic hormone signals can be reduced $^{37}$ and some key factors, such as protein kinases B (Akt) involved in signalling pathways, seem to be decreased or partially inactivated in COPD patients ${ }^{47,48}$. Moreover, nuclear apoptosis has also been reported in muscle tissue of COPD patients ${ }^{49}$. The significance of this finding is unclear as muscle cell is a syncytium (several nuclei in the same cell $)^{49}$. Since muscle apoptosis results in pauci-nuclear fibres, it has been suggested that it would determine a decrease in protein synthesis (nuclear muscle wasting) ${ }^{3}$. On the other hand, protein catabolism is increased due to multiple mechanisms ${ }^{11}$. In COPD, the most relevant catabolic system for muscle proteins is probably the one linked to proteasome ${ }^{11}$. This cell corpuscle degrades proteins, with or without prior ubiquitination, and its activity is greatly increased in underweight COPD patients ${ }^{50}$. However, ubiquitination needs the intervention of atrogenin-1 and MuRF1, both regulated by FoxO transcription factors, which are overexpressed in skeletal muscles of COPD patients ${ }^{51-53}$. Calpains, proteolytic enzymes that are very abundant in skeletal muscles and can increase their action by factors such as a reduction in physical activity, also seem to be involved in the loss of muscle mass of these patients ${ }^{54}$. Autophagy is another cellular event that is also upregulated in muscles of COPD patients with low body weight ${ }^{54,55}$. This process, closely related to lysosome enzymes (such as lipases, glycosidases, and cathepsins), occurs through the autophagosome-lysosome system and is a physiological mechanism of protein degradation ${ }^{54}$. Its abnormal increase would also lead to the loss of proteostasis observed in patients. Interestingly, there is some evidence supporting a probable role for epigenetic mechanisms such as lysine-hyperacetylation of histones that may play a relevant role in some of these pathways involved in protein hypercatabolism occurring in $\mathrm{COPD}^{55}$.

\section{INFLAMMATION AND OXIDATIVE STRESS}

Both phenomena are closely interrelated and have been demonstrated in COPD patients, both at the systemic level and in 
lungs, muscles, and adipose tissue $24,49,50,56$. Their deleterious action may be direct or through the activation of other biological processes and metabolic pathways that also favour disturbances in nutritional status. Inflammation is involved in the aforementioned apoptosis and autophagy, also activating other catabolic systems ${ }^{3}$. Reciprocally, different factors such as exacerbations, hypoxia, inactivity, or intense exercise are able to increase the baseline levels of inflammation and oxidative stress in COPD patients $^{23,24,57}$.

\section{Other tissues}

Most studies of weight loss in COPD patients have focused on skeletal muscle tissue and much less attention has been devoted to other tissues such as fat or bone. However, there is evidence that they are also affected by nutritional abnormalities associated with this lung disease. As already mentioned, bone involvement is very common in COPD patients (20$60 \%)^{39,58}$. Regarding fat mass, this can also be reduced in some patients, particularly in those with advanced stages of COPD and cachexia $^{59}$. However, the mechanism of this loss is unclear since lipolysis seems to be preserved $^{3}$. In addition, the adipose tissue is involved in the production of biological substances that can contribute to the low body weight of the patients. In this regard, some authors have reported an increase in adiponectin and other inflammatory mediators in the fat of COPD patients, along with a reduction in the levels of leptin ${ }^{60,61}$. Factors that have been involved in the loss of either adipose or bone tissues are similar to many of those that have been implicated in muscle mass reductions (smoking, inactivity, systemic inflammation, metabolic imbalance, etc. $)^{3}$.

\section{THERAPEUTIC INTERVENTIONS}

As diverse factors and mechanisms are involved in weight and muscle mass loss in COPD, the therapeutic approach should be multidimensional (Fig. 5). Inappropriate lifestyle habits must be corrected, avoiding smoking and alcohol, increasing the level of physical activity, and improving the diet quality. In addition, whenever possible, those drugs known to have a deleterious effect on nutritional status, such as systemic steroids, should be avoided. Furthermore, and as a second step in the treatment, appropriate dietary supplements can be used and, in the most extreme cases, even drugs with anabolic properties can be prescribed.

\section{Diet}

Some simple tips, such as increasing the intake of protein-rich foods (especially those containing polyunsaturated fatty acids), fibre, and the vitamins where they are most deficient (A, B6, B9, B12, C, D, and E), seem to be sufficient to maintain and even regain weight in many COPD patients with nutritional deficiency ${ }^{62}$. In fact, a healthy diet and diet interventions can even delay the onset and progression of COPD ${ }^{63-65}$. In this regard, a diet rich in fruits and vegetables seem to have a positive influence on lung function and mortality ${ }^{63}$. Moreover, it is important that diet should be rich in fibres as this has demonstrated a positive impact on delaying 


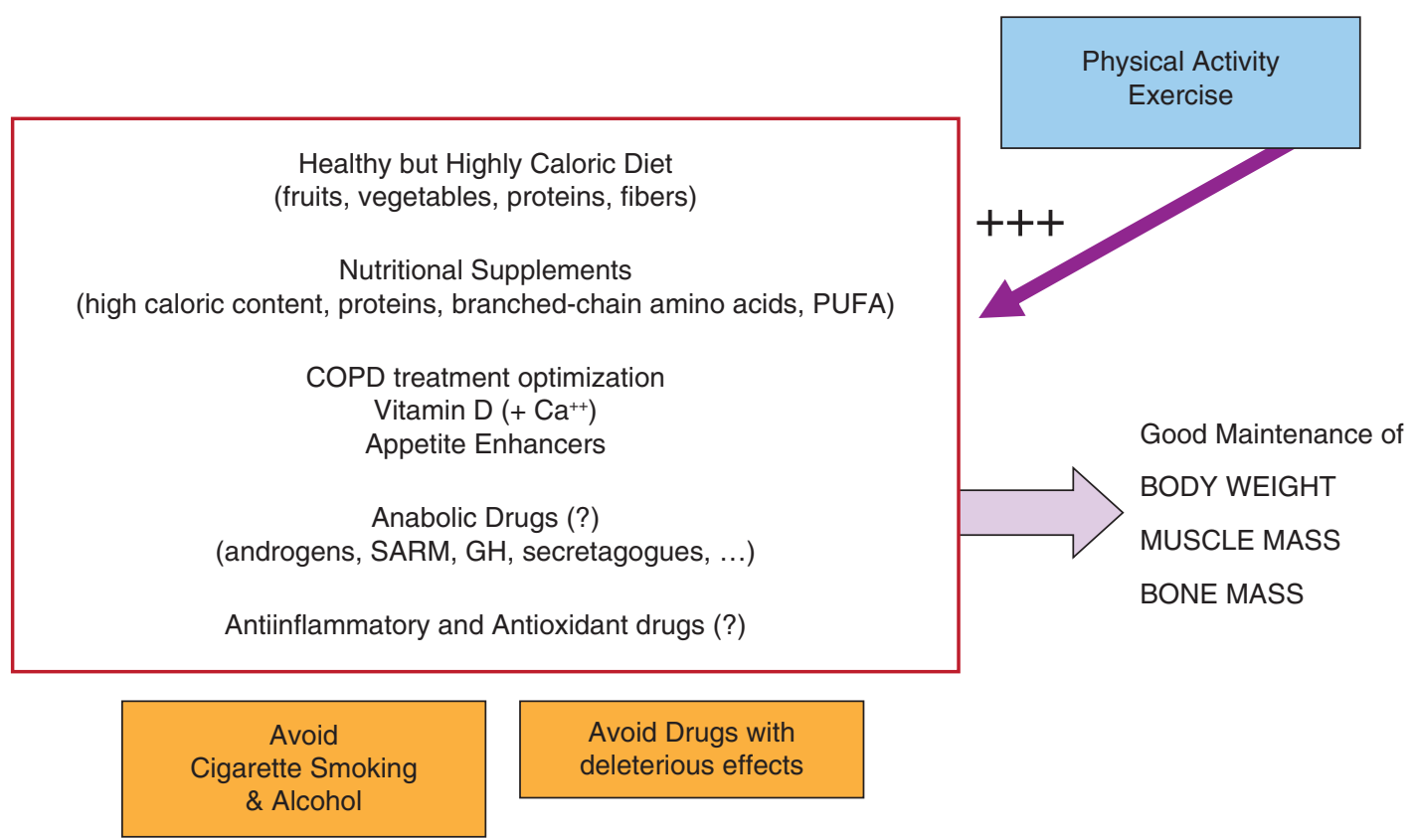

FigurE 5. Therapeutic measures that can help in body weight, fat-free mass, and bone mass gain and/or maintenance in COPD patients. GH: growth hormone; PUFA: polyunsaturated fatty acids; SARM: Selective androgen receptor modulators.

the onset and progression of COPD, probably because of its effects on the intestinal microbiome ${ }^{66}$.

\section{Nutritional supplements}

Nutritional supplements can be used as an adjunct to an adequate diet to improve its effects. In general, the supplements should provide an appropriate amount of calories, as well as proteins and amino acids that would allow an adequate protein synthesis ${ }^{11}$. Liquid supplements with high-caloric content can help in restoring weight and muscle mass in these patients ${ }^{67}$. It is important to note that the source of amino acids and proteins is also very relevant. In this regard, supplements derived from milk seem to get better amino acid concentrations than those obtained from soybean ${ }^{68}$. Also, proteins from whey are absorbed very efficiently by the bowel, and their amino acid composition allows rapid initiation of protein synthesis ${ }^{11}$. One issue to be taken into account is that COPD patients, especially those with muscle mass loss, have low concentrations of branched-chain amino acids ${ }^{69}$, so it would be beneficial to include these in the nutritional supplements. Moreover, it has been shown that their administration also improves patients' muscle metabolism ${ }^{69}$. As happens with anabolic drugs, the combination of dietary supplements with moderate physical activity enhances the nutritional effects of therapy, also being accompanied by clinical and functional improvements ${ }^{2,32,67}$. 
Finally, it has also been reported that the administration of polyunsaturated fatty acids, such as omega-3, improves the exercise capacity of patients, although its effects on lean body mass are more controversial ${ }^{70}$.

In summary, probably the best approach for a nutritional intervention in malnourished COPD patients is to modify their habits in order to achieve a healthy and balanced diet, and administer high-caloric supplements, enriched with proteins, amino acids (especially branched chain amino acids) and polyunsaturated fatty acids as well as vitamin combinations.

\section{Appetite enhancers}

Megestrol, an oral progesterone derivative, has been used among other drugs. However, the results in underweight COPD patients have been disappointing ${ }^{71}$.

\section{Anabolic drugs}

Most anabolic drugs are of a hormonal nature, related to androgens or GH. Testosterone, which can be administered either intramuscularly or transcutaneously, is in the former group. It enhances protein synthesis and decreases protein breakdown, thereby increasing muscle mass ${ }^{37}$. However, testosterone also increases lipolysis, with consequent loss of fat mass, and has other undesirable side effects. Substances with a similar androgenic effect but also important side effects are oxandrolone, which can be administered orally, and nandrolone ${ }^{36,37}$. Unfortunately, in most of the studies performed in COPD patients, these drugs are able to increase muscle mass, but this is not associated to parallel benefits in functional properties $^{3,36}$. More recently, some trials have been performed with selective androgen receptor modulators, which have anabolic actions similar to testosterone but fewer undesirable side effects ${ }^{3,72}$. However, the results are still controversial.

Growth hormone, in turn, has a powerful anabolic effect not only at the skeletal muscle level, by increasing protein synthesis and inhibiting its destruction, but also because it increases the available calcium for building new bone. This hormone can be administered subcutaneously and is able to increase body weight and muscle mass in COPD patients with malnutrition ${ }^{73}$. Unfortunately, this effect is not associated with a clear functional improvement and side effects can become important ${ }^{3,73}$. Therefore, administration of GH secretagogues (substances that promote synthesis and/or release of the endogenous hormone) have been used as an alternative. The best known is ghrelin, which is physiologically synthesized by various tissues (including the lung). It is administered intravenously and its effects are those of GH itself, but ghrelin also stimulates the appetite and has anti-inflammatory properties. The results in underweight COPD patients are controversial. In some cases it improved weight and lean mass with good functional results ${ }^{74}$, but in other studies the effects have been much more modest. Another secretagogue is tesamorelin, which is more stable and can be administered subcutaneously. In COPD patients it appears to improve lean muscle mass and strength, with few side effects ${ }^{75}$. However, definitive results are pending. 
Many other GH secretagogues, such as capromorelin, examorelin or sermorelin, are currently under study.

\section{COPD treatments}

Bronchodilators can reduce respiratory symptoms and work of breathing, which in turn would allow the patient to increase the level of physical activity. Something similar would happen with the instrumental reduction of pulmonary hyperinflation through endoscopic or surgical techniques. Moreover, an appropriate treatment of COPD exacerbations may prevent increases in systemic inflammation and reduce the period of severe gas exchange alterations and physical inactivity.

\section{Vitamin D supplementation}

Previous sections have alluded to the common vitamin D deficit showed by COPD patients. It is therefore appropriate to administer supplements of this vitamin along with calcium, and try to increase the hours of outdoor patient activity.

\section{Anti-inflammatory and antioxidant drugs}

Since inflammation and oxidative stress are involved in the pathogenesis of COPD, different drugs have been tested to neutralize these phenomena. However, only very few studies have focused on the effects of these drugs on weight and fat-free mass loss. Infliximab, for instance, which has been used to counterbalance the effects of tumour necrosis factor- $\alpha$, did not show clear effects on either the lung disease or systemic inflammation, having important side effects ${ }^{76}$. Moreover, although one study evidenced an improvement in exercise capacity, no changes have been observed in BMI or FFMI when this drug was used in underweight COPD patients ${ }^{76}$. Other drugs such as tocilizumab (anti IL-6), anakinra or canakinumab (both anti-IL1) either have not been tested in these patients or have not shown significant changes in nutritional parameters ${ }^{77}$. Regarding antioxidants, ascorbate administration appears to reduce systemic oxidative stress, improving muscle function, although no effects have been reported on patients' nutritional status $^{78}$. Similar effects have been obtained with $\mathrm{N}$-acetylcysteine and other antioxidants, both in animal models and COPD patients ${ }^{79}$.

\section{Other therapeutic strategies}

It has recently been suggested that inhibitors of NF-kB and MAPK could be useful in treating cachexia by reducing oxidation and protein catabolism and autophagy. However, there is still a lack of studies in underweight COPD patients ${ }^{80}$.

\section{OBESITY AND COPD}

It has already been mentioned that a significant percentage of COPD patients $(20-30 \%)$ are obese, as defined by a BMI $>30 \mathrm{~kg} / \mathrm{m}^{2}$ $6,13,81,82$. This proportion reaches two thirds of patients if those with overweight (BMI 25.0$29.9 \mathrm{~kg} / \mathrm{m}^{2}$ ) are added ${ }^{6,81,82}$, being clearly higher than that observed in the general population ${ }^{6}$. Obesity can also be diagnosed based on body composition, with the thresholds for 
fat mass index (FMI) established at $\geq 6.6 \mathrm{~kg} / \mathrm{m}^{2}$ in men and $\geq 9.5 \mathrm{~kg} / \mathrm{m}^{2}$ in women, and those for the percentage of body fat obesity in $\geq 25 \%$ for men and $\geq 35 \%$ for women ${ }^{81}$. Obesity is not necessarily associated with maintenance of muscle mass, since relatively often this tissue is replaced by fat, especially in women. Hence the need to determine not only anthropometric variables but different body compartments. For obesity associated muscle wasting, some authors use the term "sarcopenic obesity". Paradoxically, mild-to-moderate obesity appears to be associated with lower mortality in COPD patients ${ }^{83}$. The most likely explanation is that, like in other critical circumstances, energy reserves linked to obesity partially counterbalance the increased catabolism that is characteristic of severe acute illness.

The causes of obesity associated with COPD do not differ substantially from those affecting the general population of the Western world, but are probably more accentuated: a low level of physical activity, inappropriate diet (it has been shown that COPD patients with abdominal obesity consume a high amount of calories but low quantities of proteins and micronutrients), and other unhealthy habits ${ }^{6}$. Obesity can also be caused by hormonal changes linked to COPD, its comorbidities, and/or treatments (i.e. steroids) ${ }^{60}$. The consequences of obesity derive largely from cardiovascular and metabolic complications and the potential association with a hypoventilation syndrome ${ }^{84,85}$. In addition, obese patients have a higher level of dyspnea than patients with normal $\mathrm{BMI}^{6,82}$.

To date there is a lack of consensus for recommendations in the management of obesity in COPD patients. However, it seems reasonable to suggest a slow and moderate weight reduction and prevention of cardiovascular and metabolic complications. For this, it should be recommended to improve the quality of diet and increase physical activity, if necessary with a relatively low-intensity training program ${ }^{86}$. With these simple measures, most patients will reduce weight but maintain muscle mass, therefore improving exercise capacity and health-related quality of life 82,86 . Surgical or endoscopic treatments may be necessary to achieve weight reduction in extreme obesity. Although there are no specific studies in COPD, it has been reported that surgical weight reduction may improve spirometric values ${ }^{87}$ and ventilation/perfusion relationships ${ }^{88}$, reducing bronchial hyperactivity ${ }^{89}$, cardiovascular morbidity and mortality ${ }^{90}$, and systemic inflammome ${ }^{91}$ in morbid obesity. However, it should also be taken into account that the presence of abnormal spirometric values increases the risk of bariatric surgery $^{92}$.

\section{CONCLUSIONS}

Nutritional disorders are frequently found in COPD patients, being diagnosed through anthropometry and determination of different body components. Low body weight and muscle mass result in muscle dysfunction, impairment in exercise capacity, and worse outcomes, including increased mortality. These nutritional abnormalities are caused by the interaction of different factors such as smoking, low physical activity, systemic inflammation, and an imbalance between caloric intake and energy expenditure, which favour protein catabolism. The treatment of underweight 
patients includes improvement of lifestyle habits, dietary supplements and, in some particular cases, the use of anabolic drugs. Obesity is also very prevalent in COPD patients, being associated with cardiovascular and metabolic comorbidities. However, moderate obesity seems to have a protective role against mortality. Therefore, its management must be cautious and should include improvements in lifestyle habits.

\section{ACKNOWLEDGEMENTS}

We thank Jonathan McFarland for his help in editing this manuscript.

\section{CONFLICT OF INTEREST}

\author{
The work was partially funded by Grants \\ 2014-602525 from the EC (FW7), SAF2014-54371 \\ and CIBERES from the Spanish Government, \\ 2014SGR424 from the Catalan Government, \\ and SEPAR 2014 and 2015.
}

\section{REFERENCES}

1. Global Initiative for Chronic Obstructive Lung Disease (GOLD). Available at: http://www.goldcopd.org/ (Accessed November 2016).

2. Schols AM, Slangen J, Volovics L, Wouters EF. Weight loss is a reversible factor in the prognosis of chronic obstructive pulmonary disease. Am J Respir Crit Care Med. 1998;157:1791-7.

3. Gea J, Martínez-Llorens J, Barreiro E. [Nutritional abnormalities in chronic obstructive pulmonary disease]. Med Clin (Barc). 2014;143:78-84.

4. Swallow EB, Reyes D, Hopkinson NS, et al. Quadriceps strength predicts mortality in patients with moderate to severe chronic obstructive pulmonary disease. Thorax. 2007;62:115-20.

5. Shrikrishna D, Patel M, Tanner RJ, et al. Quadriceps wasting and physical inactivity in patients with COPD. Eur Respir J. 2012;40:1115-22.

6. Vozoris NT, O'Donnell DE. Prevalence, risk factors, activity limitation and health care utilization of an obese, population-based sample with chronic obstructive pulmonary disease. Can Respir J. 2012;19:e18-24.

7. Wan ES, Cho MH, Boutaoui N, et al. Genome-wide association analysis of body mass in chronic obstructive pulmonary disease. Am J Respir Cell Mol Biol. 2011;45:304-10.
8. Vermeeren MA, Creutzberg EC, Schols AM, et al. Prevalence of nutritional depletion in a large out-patient population of patients with COPD. Respir Med. 2006;100:1349-55.

9. Balcells E, Antó JM, Gea J, et al. Characteristics of patients admitted for the first time for COPD exacerbation. Respir Med. 2009;103:1293-302.

10. Ausin P, Martinez-Llorens J, Sabate-Bresco M, Casadevall C, Barreiro E, Gea J. Sex differences in function and structure of the quadriceps muscle in COPD patients. Chron Resp Dis. [In press].

11. Barreiro E, Gea J. Amino acid and protein metabolism in pulmonary diseases and nutritional abnormalities: A special focus on Chronic Obstructive Pulmonary Disease. Chapter 12. In: The molecular nutrition of amino acids and proteins. Dardevet D (ed). Elsevier 2016:145-60.

12. Mahan LK, Escott-Stump S (eds). Krause's food, nutrition \& diet therapy 10th edition, Philadelphia (Pa): W.B. Saunders Co; 2000:970-86.

13. World Health Organization (WHO). BMI classification. Available at: apps. who.int/bmi/index.jsp?introPage=intro_3.html (Accessed August 2016).

14. Schols AM, Wouters EF, Soeters PB, Westerterp KR. Body composition by bioelectrical-impedance analysis compared with deuterium dilution and skin-fold anthropometry in patients with chronic obstructive pulmonary disease. Am J Clin Nutr. 1991;53:421-4.

15. Coin A, Sergi G, Minicuci N, et al. Fat-free mass and fat mass reference values by dual-energy X-ray absorptiometry (DEXA) in a 20-80 year-old Italian population. Clin Nutr. 2008;27:87-94.

16. Greening NJ, Harvey-Dunstan TC, Chaplin EJ, et al. Bedside assessment of quadriceps muscle by ultrasound after admission for acute exacerbations of chronic respiratory disease. Am J Respir Crit Care Med. 2015;192:810-6.

17. Hamaoka T, Tatsumi K, Saito Y, et al. Metabolic activity in skeletal muscles of patients with non-hypoxaemic chronic obstructive pulmonary disease studied by 31P-magnetic resonance spectroscopy. Respirology. 2005;10: 164-70.

18. Debigaré R, Marquis K, Côté $\mathrm{CH}$, et al. Catabolic/anabolic balance and muscle wasting in patients with COPD. Chest. 2003;124:83-9.

19. Sancho-Muñoz A, Trampal C, Pascual S, et al. Muscle glucose metabolism in chronic obstructive pulmonary disease patients. Arch Bronconeumol. 2014;50:221-7.

20. Miravitlles M, Soler-Cataluña JJ, Calle M, et al. Spanish guideline for COPD (GesEPOC). Update 2014. Arch Bronconeumol. 2014;50(Suppl 1):1-16.

21. Celli BR, Cote CG, Marin JM, et al. The body-mass index, airflow obstruction, dyspnea, and exercise capacity index in chronic obstructive pulmonary disease. N Engl J Med. 2004;350:1005-12.

22. Gimeno-Santos E, Frei A, Steurer-Stey C, et al. Determinants and outcomes of physical activity in patients with COPD: a systematic review. Thorax. 2014;69:731-9.

23. Laveneziana P, Palange P; ERS Research Seminar Faculty. Physical activity, nutritional status and systemic inflammation in COPD. Eur Respir J. 2012; 40:522-9.

24. Barreiro E, Rabinovich R, Marin-Corral J, Barberà JA, Gea J, Roca J. Chronic endurance exercise induces quadriceps nitrosative stress in patients with severe COPD. Thorax. 2009;64:13-9.

25. Barreiro E, Peinado VI, Galdiz JB, et al. Cigarette smoke-induced oxidative stress: A role in chronic obstructive pulmonary disease skeletal muscle dysfunction. Am J Respir Crit Care Med. 2010;182:477-88.

26. Petersen AM, Magkos F, Atherton P, et al. Smoking impairs muscle protein synthesis and increases the expression of myostatin and MAFbx in muscle. Am J Physiol Endocrinol Metab. 2007;293:E843-8.

27. Grant BF, Hasin DS, Chou SP, Stinson FS, Dawson DA. Nicotine dependence and psychiatric disorders in the United States: Results from the National Epidemiologic Survey on Alcohol and Related Conditions. Arch Gen Psychiatry. 2004;61:1107-15.

28. Ryynänen OP, Soini EJ, Lindqvist A, Kilpeläinen M, Laitinen T. Bayesian predictors of very poor health related quality of life and mortality in patients with COPD. BMC Med Inform Decis Mak. 2013;13:34.

29. Steiner JL, Lang CH. Dysregulation of skeletal muscle protein metabolism by alcohol. Am J Physiol Endocrinol Metab. 2015;308:E699-712. 
30. Chambaneau A, Filaire M, Jubert L, Bremond M, Filaire E. Nutritional intake, physical activity and quality of life in COPD Patients. Int J Sports Med. 2016;37:730-7.

31. Van de Bool C, Mattijssen-Verdonschot C, van Melick PP, et al. Quality of dietary intake in relation to body composition in patients with chronic obstructive pulmonary disease eligible for pulmonary rehabilitation. Eur J Clin Nutr. 2014;68:159-65.

32. Schols AM, Soeters PB, Mostert R, Saris WH, Wouters EF. Energy balance in chronic obstructive pulmonary disease. Am Rev Respir Dis. 1991;143: 1248-52.

33. Raguso CA, Luthy C. Nutritional status in chronic obstructive pulmonary disease: Role of hypoxia. Nutrition. 2011;27:138-43.

34. Jaitovich A, Angulo M, Lecuona E, et al. High $\mathrm{CO}_{2}$ levels cause skeletal muscle atrophy via AMP-activated kinase (AMPK), FoxO3a protein, and musclespecific Ring finger protein 1 (MuRF1). J Biol Chem. 2015;290:9183-94.

35. Laghi F, Langbein WE, Antonescu-Turcu A, Jubran A, Bammert C, Tobin MJ. Respiratory and skeletal muscles in hypogonadal men with chronic obstructive pulmonary disease. Am J Respir Crit Care Med. 2005;171:598-605.

36. Creutzberg EC, Casaburi R. Endocrinological disturbances in chronic obstructive pulmonary disease. Eur Respir J. 2003;22(Suppl 46):76-80s.

37. Maltais F, Decramer M, Casaburi R, et al. An official American Thoracic Society/European Respiratory Society statement: update on limb muscle dysfunction in chronic obstructive pulmonary disease. Am J Respir Crit Care Med. 2014;189:e15-62.

38. Janssens W, Bouillon R, Claes B, et al. Vitamin D deficiency is highly prevalent in COPD and correlates with variants in the vitamin D-binding gene. Thorax. 2010;65:215-20.

39. Lehouck A, Boonen S, Decramer M, Janssens W. COPD, bone metabolism, and osteoporosis. Chest. 2011;139:648-57.

40. Sergi G, Coin A, Marin S, et al. Body composition and resting energy expenditure in elderly male patients with chronic obstructive pulmonary disease. Respir Med. 2006;100:1918-24.

41. Hasselgren PO, Alamdari N, Aversa Z, Gonnella P, Smith IJ, Tizio S. Corticosteroids and muscle wasting: Role of transcription factors, nuclear cofactors, and hyperacetylation. Curr Opin Clin Nutr Metab Care. 2010;13:423-8.

42. Barreiro E, Gea J, Corominas JM, Hussain SN. Nitric oxide synthases and protein oxidation in the quadriceps femoris of patients with chronic obstructive pulmonary disease. Am J Respir Cell Mol Biol. 2003;29:771-8.

43. Barreiro E, de la Puente B, Minguella J, et al. Oxidative stress and respiratory muscle dysfunction in severe chronic obstructive pulmonary disease. Am J Respir Crit Care Med. 2005;171:1116-24.

44. Puig-Vilanova E, Aguiló R, Rodríguez-Fuster A, Martínez-Llorens J, Gea J, Barreiro E. Epigenetic mechanisms in respiratory muscle dysfunction of patients with chronic obstructive pulmonary disease. PLoS One. 2014;9: e111514.

45. Morrison WL, Gibson JN, Scrimgeour C, Rennie MJ. Muscle wasting in emphysema. Clin Sci (Lond). 1988;75:415-20.

46. Bohé J, Low A, Wolfe RR, Rennie MJ. Human muscle protein synthesis is modulated by extracellular, not intramuscular amino acid availability: a dose-response study. J Physiol. 2003;552:315-24.

47. Guo Y, Gosker HR, Schols AM, et al. Autophagy in locomotor muscles of patients with chronic obstructive pulmonary disease. Am J Respir Crit Care Med. 2013;188:1313-20.

48. Costes F, Gosker H, Feasson L, et al. Impaired exercise training-induced muscle fiber hypertrophy and Akt/mTOR pathway activation in hypoxemic patients with COPD. J Appl Physiol (1985). 2015;118:1040-9.

49. Barreiro E, Ferrer D, Sanchez F, et al. Inflammatory cells and apoptosis in respiratory and limb muscles of patients with COPD. J Appl Physiol. 2011;111:808-17.

50. Fermoselle C, Rabinovich R, Ausín P, et al. Does oxidative stress modulate limb muscle atrophy in severe COPD patients? Eur Respir J. 2012;40:851-62.

51. Debigaré R, Côte $\mathrm{CH}$, Hould FS, LeBlanc $\mathrm{P}$, Maltais F. In vitro and in vivo contractile properties of the vastus lateralis muscle in males with COPD. Eur Respir J. 2003;21:273-8
52. Doucet M, Russell AP, Léger B, et al. Muscle atrophy and hypertrophy signaling in patients with chronic obstructive pulmonary disease. Am J Respir Crit Care Med. 2007;176:261-9.

53. Plant PJ, Brooks D, Faughnan M, et al. Cellular markers of muscle atrophy in chronic obstructive pulmonary disease. Am J Respir Cell Mol Biol. 2010; 42:461-71.

54. Hussain SN, Sandri M. Role of autophagy in COPD skeletal muscle dysfunction. J Appl Physiol. 2012;114:1273-81.

55. Puig-Vilanova E, Rodriguez DA, Lloreta J, et al. Oxidative stress, redox signaling pathways, and autophagy in cachectic muscles of male patients with advanced COPD and lung cancer. Free Radic Biol Med. 2015;79:91-108.

56. Van den Borst B, Gosker HR, Wesseling G, et al. Low-grade adipose tissue inflammation in patients with mild-to-moderate chronic obstructive pulmonary disease. Am J Clin Nutr. 2011;94:1504-12.

57. Karadag F, Karul AB, Cildag O, Yilmaz M, Ozcan H. Biomarkers of systemic inflammation in stable and exacerbation phases of COPD. Lung. 2008; 186:403-9.

58. Ionescu AA, Schoon E. Osteoporosis in chronic obstructive pulmonary disease. Eur Respir J Suppl. 2003;46:64-75s.

59. Yamamoto C, Yoneda T, Yoshikawa M, et al. The relationship between a decrease in fat mass and serum levels of TNF-alpha in patients with chronic obstructive pulmonary disease. Nihon Kyobu Shikkan Gakkai Zasshi. 1997;35:1191-5.

60. Tkacova R, Ukropec J, Skyba P, et al. Increased adipose tissue expression of proinflammatory CD40, MKK4 and JNK in patients with very severe chronic obstructive pulmonary disease. Respiration. 2011;81:386-93.

61. Kirdar S, Serter M, Ceylan E, Sener AG, Kavak T, Karadag F. Adiponectin as a biomarker of systemic inflammatory response in smoker patients with stable and exacerbation phases of chronic obstructive pulmonary disease. Scand J Clin Lab Invest. 2009;69:219-24.

62. Weekes CE, Emery PW, Elia M. Dietary counselling and food fortification in stable COPD: A randomised trial. Thorax. 2009;64:326-31.

63. Walda IC, Tabak C, Smit HA, et al. Diet and 20-year chronic obstructive pulmonary disease mortality in middle-aged men from three European countries. Eur J Clin Nutr. 2002;56:638-43.

64. Varraso R, Barr RG, Willett WC, Speizer FE, Camargo CA. Fish intake and risk of chronic obstructive pulmonary disease in 2 large US cohorts. Am J Clin Nutr. 2015;101:354-61.

65. Fonseca Wald EL, van den Borst B, Gosker HR, Schols AM. Dietary fibre and fatty acids in chronic obstructive pulmonary disease risk and progression: a systematic review. Respirology. 2014;19:176-84.

66. Varraso R, Willett WC, Camargo CA. Prospective study of dietary fiber and risk of chronic obstructive pulmonary disease among US women and men. Am J Epidemiol. 2010;171:776-84.

67. Efthimiou J, Fleming J, Gomes C, Spiro SG. The effect of supplementary oral nutrition in poorly nourished patients with chronic obstructive pulmonary disease. Am Rev Respir Dis. 1988;137:1075-82.

68. Fouillet H, Mariotti F, Gaudichon C, Bos C, Tomé D. Peripheral and splanchnic metabolism of dietary nitrogen are differently affected by the protein source in humans as assessed by compartmental modeling. J Nutr. 2002;132 125-33.

69. Engelen MP, Rutten EP, de Castro CL, Wouters EF, Schols AM, Deutz NE Supplementation of soy protein with branched-chain amino acids alters protein metabolism in healthy elderly and even more in patients with chronic obstructive pulmonary disease. Am J Clin Nutr. 2007;85:431-9.

70. Broekhuizen R, Wouters EF, Creutzberg EC, Weling-Scheepers CA, Schols AM. Polyunsaturated fatty acids improve exercise capacity in chronic obstructive pulmonary disease. Thorax. 2005;60:376-82.

71. Weisberg J, Wanger J, Olson J, et al. Megestrol acetate stimulates weight gain and ventilation in underweight COPD patients. Chest. 2002;121:1070-8.

72. Ebner N, Springer J, Kalantar-Zadeh K, et al. Mechanism and novel therapeutic approaches to wasting in chronic disease. Maturitas. 2013;75:199-206.

73. Burdet L, de Muralt B, Schutz Y, Pichard C, Fitting JW. Administration of growth hormone to underweight patients with chronic obstructive pulmonary 
disease. A prospective, randomized, controlled study. Am J Respir Crit Care Med. 1997;156:1800-6.

74. Nagaya N, Itoh T, Murakami S, et al. Treatment of cachexia with ghrelin in patients with COPD. Chest. 2005;128:1187-93.

75. Maltais F, O'Donnell DE, Schols AM, et al. Effect of TH9507, a growth hormone releasing factor (GFR) analog, on functional performance in patients with COPD [Abstract]. Eur Respir J. 2004;24(Suppl 48):245s.

76. Rennard SI, Fogarty C, Kelsen S, et al. The safety and efficacy of infliximab in moderate to severe chronic obstructive pulmonary disease. Am J Respir Crit Care Med. 2007;175:926-34.

77. Rogliani P, Calzetta L, Ora J, Matera MG. Canakinumab for the treatment of chronic obstructive pulmonary disease. Pulm Pharmacol Ther. 2015;31: 15-27.

78. Rossman MJ, Garten RS, Groot HJ, et al. Ascorbate infusion increases skeletal muscle fatigue resistance in patients with chronic obstructive pulmonary disease. Am J Physiol Regul Integr Comp Physiol. 2013;305: R1163-70.

79. Rahman I, MacNee W. Antioxidant pharmacological therapies for COPD. Curr Opin Pharmacol. 2012;12:256-65.

80. Chacon-Cabrera A, Fermoselle C, Urtreger AJ, et al. Pharmacological strategies in lung cancer-induced cachexia: effects on muscle proteolysis, autophagy, structure, and weakness. J Cell Physiol. 2014;229:1660-72.

81. Peltz G1, Aguirre MT, Sanderson M, Fadden MK. The role of fat mass index in determining obesity. Am J Hum Biol. 2010;22:639-47.

82. O'Donnell DE, Deesomchok A, Lam YM, et al. Effects of BMI on static lung volumes in patients with airway obstruction. Chest. 2011;140:461-8.
83. Guo Y, Zhang T, Wang Z, et al. Body mass index and mortality in chronic obstructive pulmonary disease: A dose-response meta-analysis. Medicine (Baltimore). 2016;95:e4225.

84. Garcia-Aymerich J, Farrero E, Félez MA, et al. Risk factors of readmission to hospital for a COPD exacerbation: a prospective study. Thorax. 2003; 58:100-5.

85. Chebbo A, Tfaili A, Jones SF. Hypoventilation syndromes. Med Clin North Am. 2011;95:1189-202.

86. McDonald VM, Gibson PG, Scott HA, et al. Should we treat obesity in COPD? The effects of diet and resistance exercise training. Respirology. 2016;21:875-82.

87. Wei YF, Wu HD. Candidates for bariatric surgery: morbidly obese patients with pulmonary dysfunction. J Obes. 2012;2012:878371.

88. Rivas E, Arismendi E, Agustí A, et al. Ventilation/Perfusion distribution abnormalities in morbidly obese subjects before and after bariatric surgery. Chest. 2015;147:1127-34.

89. Arismendi E, Rivas E, Vidal J, et al. Airway hyperresponsiveness to mannitol in obesity before and after bariatric surgery. Obes Surg. 2015;25:1666-71.

90. Athyros VG, Tziomalos K, Karagiannis A, Mikhailidis DP. Cardiovascular benefits of bariatric surgery in morbidly obese patients. Obes Rev. 2011; 12:515-24.

91. Arismendi E, Rivas E, Agustí A, et al. The systemic inflammome of severe obesity before and after bariatric surgery. PLoS One. 2014;9:e107859.

92. Clavellina-Gaytán D, Velázquez-Fernández D, Del-Villar E, et al. Evaluation of spirometric testing as a routine preoperative assessment in patients undergoing bariatric surgery. Obes Surg. 2015;25:530-6. 